\title{
Performance of Pulverized Coal Combustion under High Temperature Air Diluted by Steam
}

\author{
Mohsen Saffari Pour and Yang Weihong \\ Division of Energy and Furnace Technology, KTH Royal Institute of Technology, 10044 Stockholm, Sweden \\ Correspondence should be addressed to Mohsen Saffari Pour; mohsensp@kth.se
}

Received 10 December 2013; Accepted 3 March 2014; Published 25 March 2014

Academic Editors: T. Basak and C. J. Ho

Copyright ( 2014 M. Saffari Pour and Y. Weihong. This is an open access article distributed under the Creative Commons Attribution License, which permits unrestricted use, distribution, and reproduction in any medium, provided the original work is properly cited.

\begin{abstract}
The high temperature air combustion (HiTAC) is an advanced promising technology for heat recovery, energy saving, and stability improvement of flame. Computational fluid dynamic (CFD) is known as an applied tool to execute HiTAC modeling. In this paper, performances of pulverized coal combustion under the high preheated and oxygen deficient air are studied by both experimental and numerical methodology. The experimental facilities have been accomplished in a HiTAC chamber with coal injection velocity that ranges from 10 to $40 \mathrm{~m} / \mathrm{s}$. In order to achieve different preheated temperatures, the combustion air in such system is diluted by variable steam percentages from 0 to $44 \%$. Results of mathematical simulation and experimental tests present convincible agreement through whole region. It is concluded that $\mathrm{NO}_{X}$ emission is reduced by increasing the steam percentage in the oxidizer due to decreasing the flame temperature. Besides, graphical contours show that by adding more steam to oxidizer composition, the oxygen concentration decreased. Additionally, results show that when the injection speed of fuel is increased, $\mathrm{NO}_{X}$ emission is also increased, and when the injection rate of preheated air is increased, $\mathrm{NO}_{X}$ emission shows decreasing trend. Further contribution in future is needed to investigate the performance of such technologies.
\end{abstract}

\section{Introduction}

During the past decades, Coal has been primarily fueled for electric power generation because of cheap price and plenty of accessible mineral sources. After critical shortage of oil and natural gas for industrial benefits, a world wide effort is being made by scientists to develop methods for gasifying coals. Coal contains more or less properties similar to oil, so by a little modification of previous facilities, scientists can attain truthful equipment for solid state fuel instead of liquid/gas one. Once these methods are entirely developed, they will denote major source of coal utilization. The usage of gasified coal in power plant facilities will improve the combustion rate which leads a convincible clean combustion technology. Furthermore, gasified coal produces more efficient syngas that is functional for other purposes such as secondary combustion and sustainable heat recoveries.

Generally, HiTAC is a prominent technique which compromises a possible solution to pollutant emissions reduction and heat transfer uniformity [1-4]. At first, HiTAC technology is developed in Japan in a great teamwork with several researchers in all over the world. The basic feature of this technique is that highly diluted and preheated air is mixed with fuel to form a uniform volumetric combustion. This technology provides higher energy efficiency, heat recovery, and low $\mathrm{NO}_{X}$ emission. Furthermore, in comparison with ordinary combustion, increase of the reaction zone volume and uniform flame temperature distribution are important characteristics of such systems. The above benefits of HiTAC have been reported separately by Ito et al. [5] and Mörtberg et al. [6]. The results obtained by Tsuji et al. [7] showed that the use of this technology leads to a major decrease in pollutant emission like nitric oxides up to $50 \%$ and fuel consumption up to $30 \%$.

Based on history of usage behind the HiTAC technology, such technique was first applied in gaseous fuels. For clean gaseous fuels that do not contain any nitrogen fuel compounds, results illustrate very low $\mathrm{NO}_{X}$ emissions even 
if the combustion air stream is preheated to temperatures in excess of $1273 \mathrm{~K}$. The opposite case occurs in conventional combustion systems where reactions are concentrated in a thin flame front. The HiTAC has been applied in many industrial furnaces [8] especially fired with natural gas. Furthermore, it was also demonstrated that this technique may be used for combustion of light liquid fuels [9] and biogases [10].

Combustion modeling of industrial chambers is a threedimensional instance that involves numerous lateral problematic issues such as fluid and particle flow, turbulence, combustion chemistry, radiative heat transfer, and pollutants calculations. Achieving full combustion calculations due to several parameters such as human knowledge and computer powers is essentially impossible. Therefore, it is necessary to make some assumption to simplify the problem and make it more tangible. Several combustion methods support the new approaches for HiTAC technology in coal combustion such as moderate and intense low oxygen dilution (MILD) combustion [11] or flameless oxidation (FLOX) [12]. These advanced technologies illuminated the attention of researchers on combustion of heavy solid fuels. Most of the contributions on air/steam injection in a combustion chamber are reported for gas turbines and diesel engines [13-15].

$\mathrm{NO}_{X}$ emission from combustion is quite an advanced and warm topic among the researchers which work on performance and pollutant emissions from combustion. Yang and Blasiak [16] have done one of the basic researches on $\mathrm{NO}_{X}$ model in HiTAC systems, they showed that $\mathrm{NO}$ with $\mathrm{N}_{2} \mathrm{O}$-route model can give more reasonable profile of $\mathrm{NO}$ formation and increasing excess air ratio leads to increase of $\mathrm{NO}$ emission in the regenerative furnace. Khoshhal et al. [17] presented their results based on a HiTAC boiler which their observations show that the $\mathrm{NO}_{X}$ increased by increasing in temperature and oxygen concentration. Danon et al. [18] and Nabili and Blasiak [19] observed that the $\mathrm{NO}_{X}$ decreased in HiTAC furnace because the peak temperature in HiTAC furnace is decreased and the flame will be more stable than conventional systems. Khoshhal et al. [20] investigated the CFD calculation of diluted air effects in furnace and they presented high dependence of $N O_{X}$ emission on temperature, and existence of oxygen in diluted air.

Objectives of this work focused on both experimental and numerical study on performance of the pulverized coal combustion. The numerical calculations and collected data are performed for high preheated air diluted by steam in a vertical HiTAC chamber. The effects of different parameters such as mixture percentage of steam, injection velocity, and preheated temperature have been studied. The main contribution is proposed to investigate $\mathrm{NO}_{X}$ emission, heat transfer, and temperature evaluation in combustion chamber. Since pollutant emission is significantly affected by fluid flow, temperature, and oxygen concentration distributions, several figures are presented to cover them. Furthermore, additional attention is given for soot formation and total $\mathrm{NO}_{X}$ emission, as crucial factors in the performance of HiTAC systems.

\section{Experimental and Test Facilities}

The experimental facilities are declared as preheater, boiler, coal feeder, combustion chamber, and second combustion chamber in Figure 1. The volume of main combustion chamber which is modeled by numerical methods is equal to $0.28 \mathrm{~m}^{3}$ and surfeit of $2.2 \mathrm{~m}^{2}$. Two Isokinetic probes were located to collect the ash and flue gas samples for analysis. The temperature is measured by 5 thermocouples which are installed in different positions near the insulated wall. In order to fulfill the HiTAC system of coal combustion, the facilities were rebuilt and the test facilities have been developed for several years.

Numerical modeling and experimental measurements of coal combustion needs coal properties. Table 1 shows the proximate and ultimate analyses of Helsingborg coal for the experimental facilities.

\section{Numerical Methods}

The numerical models are obtained from Navier Stokes equations for mass, momentum, energy, and transport equations for scalar variables. The computational domain for HiTAC combustion chamber is defined by 238526 tetrahedral volume meshes. In this study, fluid flow is simulated by a 3D Reynolds-Averaged Navier Stokes (RANS) equation together with RNG $K-\varepsilon$ turbulence model using commercial CFD software, ANSYS FLUENT 14.0 [21]. In order to model the pollutant emission during the simulation, the $\mathrm{NO}_{X}$ and Soot models were activated. It means that to model $\mathrm{NO}_{X}$ emission, thermal $\mathrm{NO}_{X}$, prompt $\mathrm{NO}_{X}$, fuel $\mathrm{NO}_{X}$, and $\mathrm{N}_{2} \mathrm{O}$ intermediate models are considered simultaneously. During the computational area for the above models and species transport of particles, the PDE equations, the secondorder upwind schemes, segregated solution method, and the SIMPLE pressure-velocity coupling were used.

3.1. Combustion and Devolatilized Model. A competing reaction based on kinetic-diffusion scheme is used to model the coal devolatilization rate [22]. It is assumed that there are two competing reactions with one reaction leading benefits at lower temperatures and the other reaction leading benefits at higher temperatures. After the devolatilization process, the pulverized coal changes to volatiles $V_{1}$ and $V_{2}$ and the residual char of $R_{1}$ and $R_{2}$. The two competing reactions are formulated as follows:

$$
\text { pulverized coal } \begin{cases}\left(1-\propto_{1}\right) R_{1}+\propto_{1} V_{1} & \left(F_{1}\right) \\ \left(1-\propto_{2}\right) R_{2}+\propto_{2} V_{2} & \left(F_{2}\right)\end{cases}
$$

where $\propto_{1}$ takes the value of volatile matter percentage obtained in proximate analysis of coal from Table 1 and $\propto_{2}$ is given the value of 0.8 to reflect the characteristics of devolatilization at high temperature. Char chain reaction mechanism is complicated, therefore some of the important 
TABle 1: Properties of coal structure.

\begin{tabular}{|c|c|c|c|c|c|c|}
\hline \multicolumn{2}{|c|}{ Coal analysis } & Wet & Dry & Air dried & Dry ash free & Unit \\
\hline \multirow{4}{*}{ Proximate analysis } & Moisture & 6.7 & - & 0.9 & - & $\%$ \\
\hline & Ash & 11.10 & 11.9 & 11.79 & - & $\%$ \\
\hline & Volatiles & 19.41 & 20.80 & 20.61 & 23.61 & $\%$ \\
\hline & Fixed carbon & 62.79 & 67.30 & 66.69 & 76.39 & $\%$ \\
\hline \multirow{6}{*}{ Ultimate analysis } & Chlorine & 0.01 & $<0.01$ & 0.01 & 0.01 & $\%$ \\
\hline & Sulfur & 0.32 & 0.34 & 0.34 & 0.39 & $\%$ \\
\hline & Carbon & 70.91 & 76.00 & 75.32 & 86.27 & $\%$ \\
\hline & Hydrogen & 3.73 & 4.00 & 3.96 & 4.54 & $\%$ \\
\hline & Nitrogen & 1.4 & 1.50 & 1.49 & 1.70 & $\%$ \\
\hline & Oxygen & 5.78 & 6.20 & 6.14 & 7.04 & $\%$ \\
\hline \multicolumn{2}{|c|}{ High heating values (HHV) } & 28.95 & 31.03 & 30.75 & 35.22 & $\mathrm{MJ} / \mathrm{kg}$ \\
\hline \multicolumn{2}{|c|}{ Low heating values (LHV) } & 27.99 & 30.17 & 29.90 & 34.25 & $\mathrm{MJ} / \mathrm{kg}$ \\
\hline
\end{tabular}

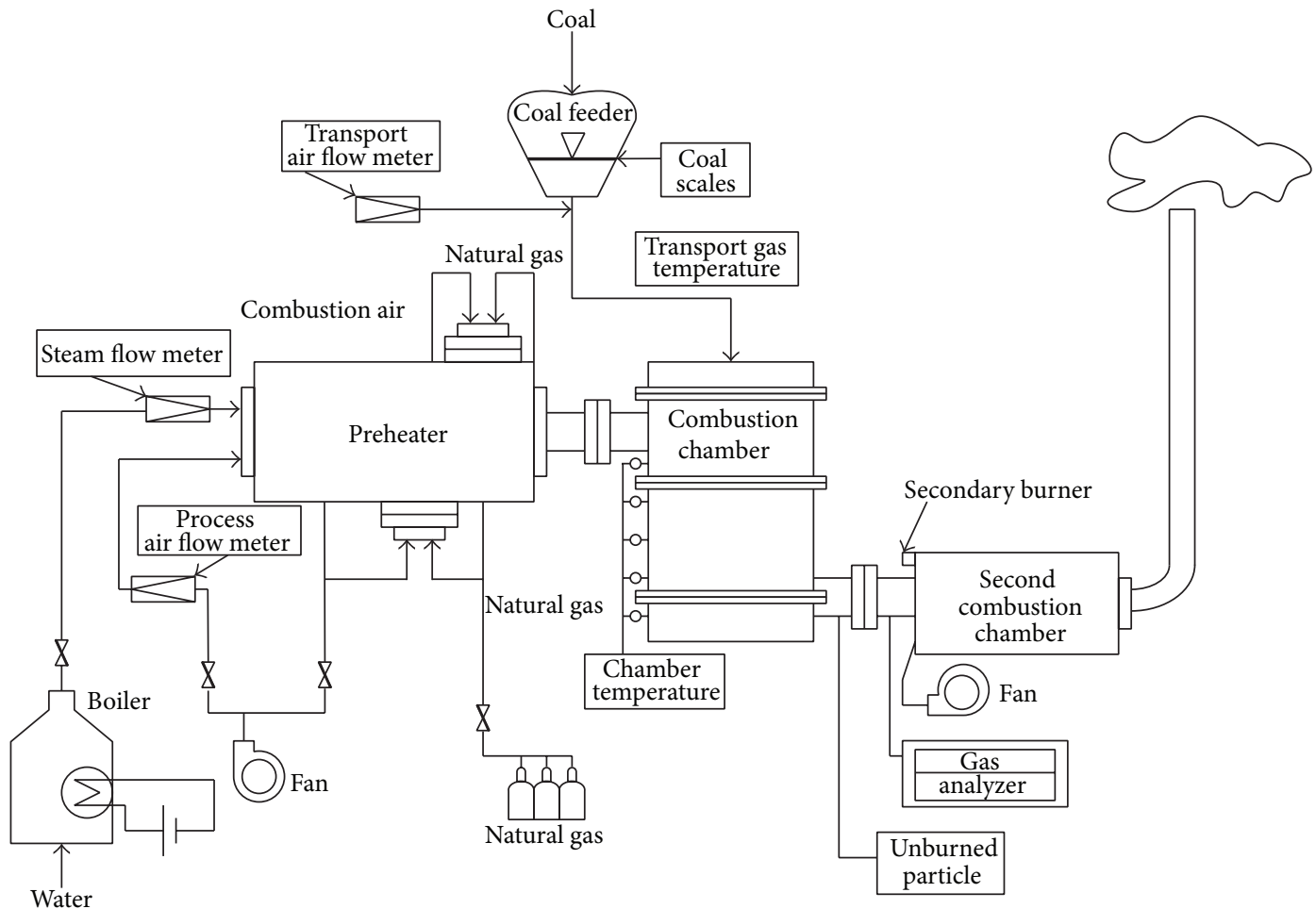

FIGURE 1: Schematic of experimental equipment.

reactions in this study are offered by the six following reactions:

$$
\begin{gathered}
\text { mv_coal }+1.614 \mathrm{O}_{2} \longrightarrow 2.763 \mathrm{H}_{2} \mathrm{O}+\mathrm{CO} \\
\mathrm{C}+0.5 \mathrm{O}_{2} \longrightarrow \mathrm{CO} \\
\mathrm{C}+\mathrm{CO}_{2} \longrightarrow 2 \mathrm{CO} \\
\mathrm{C}+\mathrm{H}_{2} \mathrm{O} \longrightarrow \mathrm{CO}+\mathrm{H}_{2} \\
\mathrm{H}_{2}+0.5 \mathrm{O}_{2} \longrightarrow \mathrm{H}_{2} \mathrm{O} \\
\mathrm{CO}+0.5 \mathrm{O}_{2} \longrightarrow \mathrm{CO}
\end{gathered}
$$

The highest encounters in modeling turbulent combustion are handling the average rate of reaction, with considering satisfactory representation of the chemistry in reactions. In this research, a two-phase volumetric reactionbased model with considering the surface particle reactions, with the eddy dissipation concept (EDC) model is used. However, in high temperature above $1300 \mathrm{~K}$, the reaction rates are mostly dependent on temperature than turbulent effects. Therefore, this model is able to predict high temperature air combustion conditions simultaneous with turbulent effects [23]. Discrete ordinate (DO) model uses for different varieties of optical thicknesses. As the optical thickness in flame region 


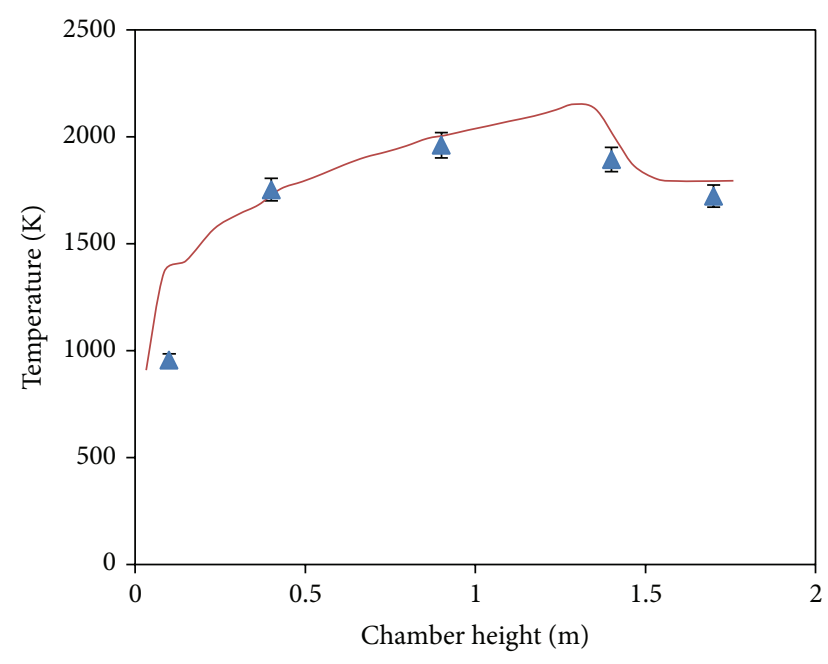

- Experimental

- CFD

FIGURE 2: Validation of CFD results.

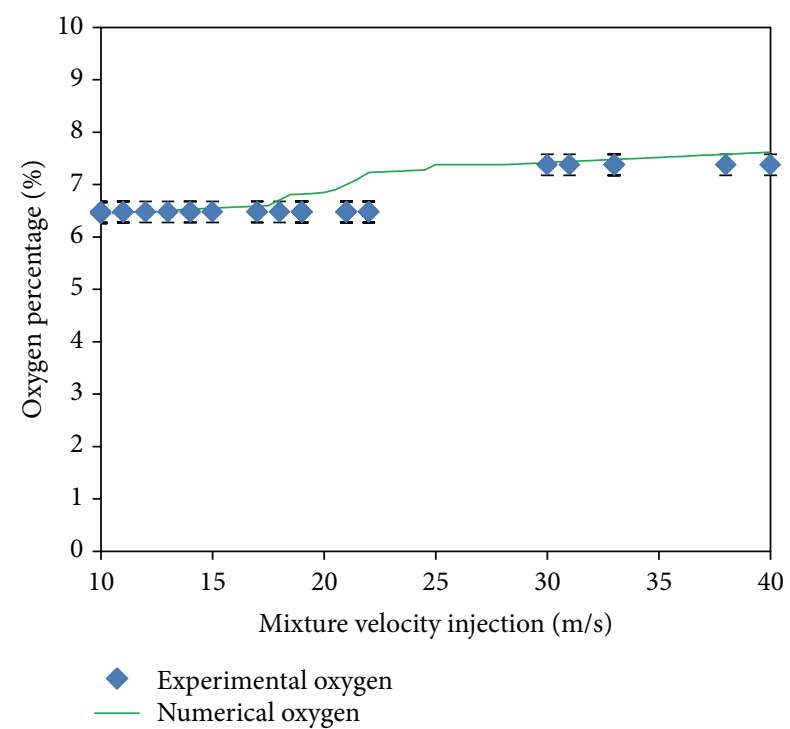

FIGURE 3: Validation of oxygen concentration.

is not distinguishable, the DO model seems acceptable for radiation calculations [24].

\section{Results and Discussions}

4.1. Validation of Experimental and CFD Results. In order to compare validity of the computational methods with the experimental measurements, the experimental data are collected by thermocouples and compared with CFD results along the center line of combustion chamber. The compared data are accomplished for $10 \mathrm{~m} / \mathrm{s} \mathrm{coal} \mathrm{injection} \mathrm{from} \mathrm{the} 5 \mathrm{~mm}$ diameter nozzle with $1050 \mathrm{~K}$ and $0.02 \mathrm{~kg} / \mathrm{s}$ oxidizer injection rate of $100 \%$ air composition.

Figure 2 shows the collected data from the experimental results in comparison with numerical calculations. Scatter

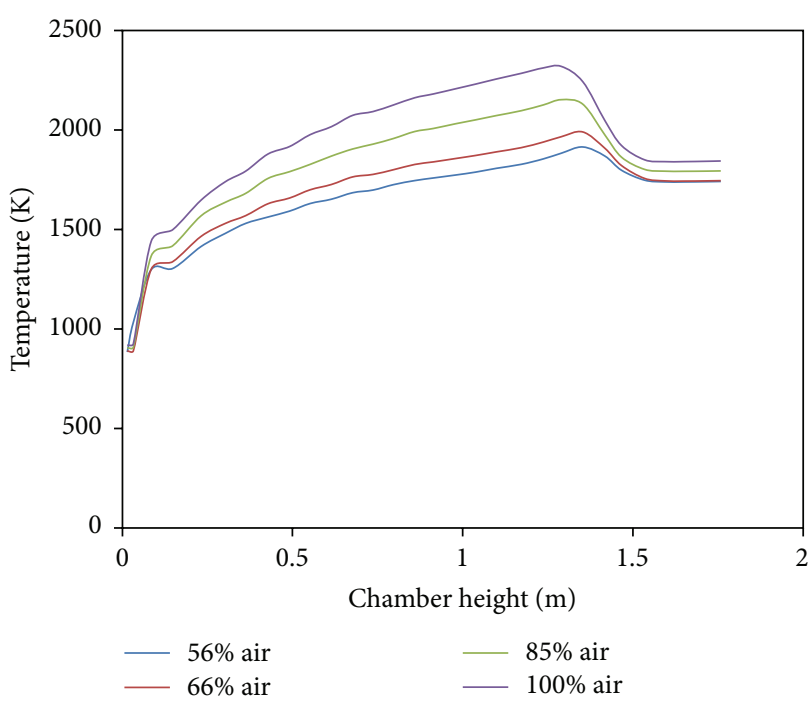

Figure 4: Temperature distribution along the chamber center line at the preheated temperature of $1050 \mathrm{~K}$.

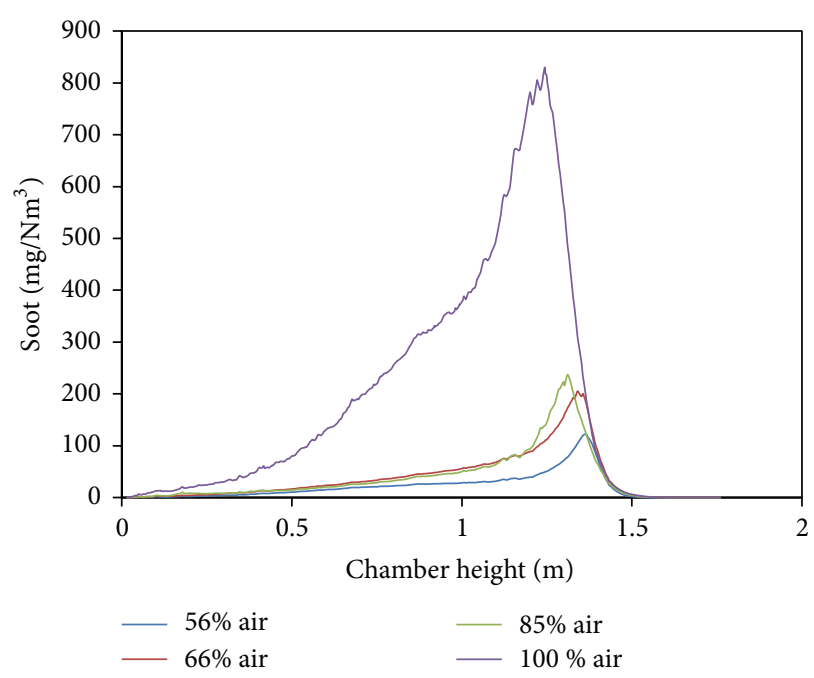

FIGURE 5: Soot formation for different steam percentages.

of plotted graphs demonstrates a good consistency in total combustion zone. Temperature validation in Figure 2 reveals the heat release from combustion that happened in a balance mode with experimental results. However, a little difference among results relates the data collecting from the center line of calculation domain and near wall experimental measurements with thermocouples.

Species concentrations validation is also considered for oxygen percentage in flue gases of HiTAC chamber. Figure 3 shows the oxygen concentration in flue gases for different coal injection velocities from the $5 \mathrm{~mm}$ diameter nozzle with $1050 \mathrm{~K}$ and $0.02 \mathrm{~kg} / \mathrm{s}$ oxidizer injection rate of $100 \%$ air composition. Besides, results show approximately $6-7 \%$ oxygen concentration in exhaust of chamber which leads a convincible validation for flue gas composition in a coal combustion system [25]. The comparison of species results at 


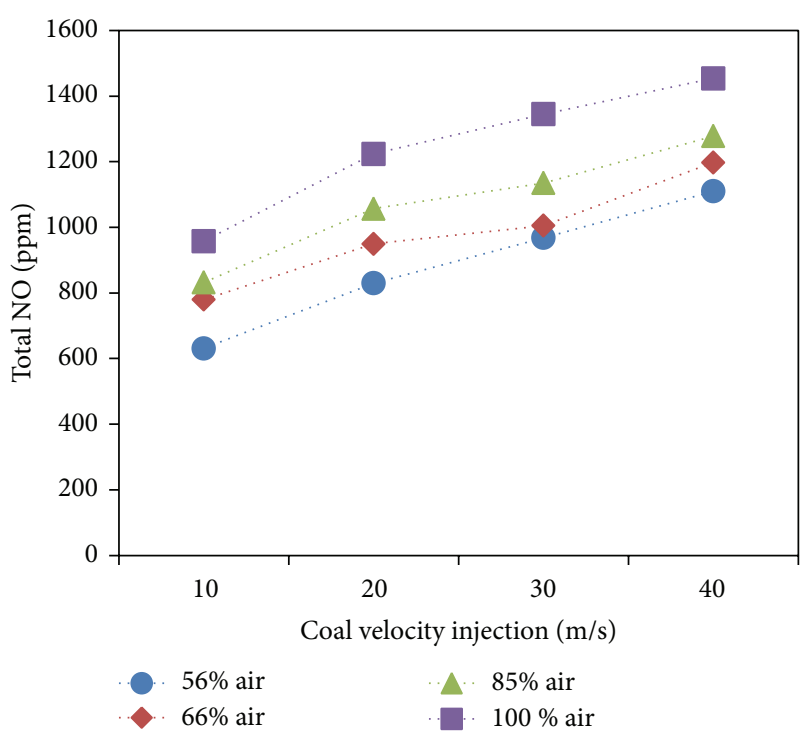

FIGURE 6: Total NO emission in combustion chamber for different coal velocity injections.

exhaust reveals that the flue gas gained enough effects from chemical reactions in reactive zone.

4.2. Effect of Steam Mixture. Figure 4 shows the temperature distribution for four different cases of oxidizer composition. The plotted curves reveal that the maximum available temperature is $2300 \mathrm{~K}$ and the minimum one is $1600 \mathrm{~K}$ in peak zones. There are two peak points in all curves, the first peak relates the stage of volumetric combustion zone and the second one represents the stage of char combustion. Additionally, turbulence effects near the injection point and fluctuation of temperature are taking place from $0.2 \mathrm{~m}$ to $1 \mathrm{~m}$ of the full height of the combustion chamber [25]. The main effect by steam is caused by dissociated $\mathrm{H}$ and $\mathrm{OH}$ radicals during the injection of oxidizer [26]. These radicals easily react in a short residence time because of their nature and react with combusted particle. The reactions of $\mathrm{H}$ and $\mathrm{OH}$ radicals with either coal particle or flue gas reduce temperature significantly.

Figure 5 presents the soot formation in combustion chamber for $10 \mathrm{~m} / \mathrm{s}$ coal injection from the $5 \mathrm{~mm}$ diameter nozzle with $1050 \mathrm{~K}$ and $0.02 \mathrm{~kg} / \mathrm{s}$ preheated air injection rate as the base case of investigations. The same trend of propagation is distinguishable for all curves, in ignition, turbulence, and char combustion zone. From this figure, it is inferred that by adding more steam to oxidizer composition, the amounts of soot decreased. Therefore, the trapped soot in upstream will be smoother than the pure air combustion because of more oxygen concentrations as reactant with carbon particles. On the other hand, the peak points in curves of Figure 5 present the trapped soot at the bottom of combustion chamber. Besides, reliable combustion evaluates by soot amounts the formation which shows the impure carbon particles due to the incomplete combustion process [27].
For further investigation on enhancement of steam on pollutant emission from coal combustion, the total pollutant $\mathrm{NO}$ is plotted in Figure 6. All curves show increasing trend by increasing temperature and coal velocity injection. In $\mathrm{NO}_{X}$ formation, it is concluded that $\mathrm{OH}$ radicals react with one of chain reactions such as $\mathrm{N}+\mathrm{OH} \rightarrow \mathrm{NO}+\mathrm{H}$ and caused NO promotion. Otherwise, formations of radicals occur in a short time and react with several chain reactions. Therefore, these chain reactions are not the only ones that $\mathrm{OH}$ radicals can react with to promote the NO significantly. Additionally, in this figure, the entire involving mechanisms of $\mathrm{NO}_{X}$ emission are considered. Because of high temperature in combustion chamber, the thermal $\mathrm{NO}_{X}$ plays a dominant role in comparison with the other $\mathrm{NO}_{X}$ mechanisms. Therefore, NO emission in HiTAC system is highly dependent on temperature than injection velocity and turbulent effects.

4.3. HiTAC Contours. In order to show a visible complementary of the temperature distribution, oxygen concentrations, and pollutant NO in our HiTAC experimental facilities, Figures 7 to 9 are proposed. The contour of temperature in Figure 7 represents the temperature distribution in combustion volume. Entire contours are selected from a surface which is located in the middle of chamber on $x-z$ plane. Figure 7 illustrates that the main flame volume is placed around the injection points, and it continues to exhaust in a defined shape. The main steam characteristic is known as high heating value (HHV) of steam to absorb the heat from reactions, in order to increase its own temperature. Additionally, the moisture in oxidizer composition cools down the facilities as well, which provides more eventual temperature in entire volume and reduces the difference between the minimum and maximum temperature peaks.

Figure 8 shows oxygen concentrations in combustion chamber volume. Contours of oxygen perfectly signify the coal nozzle and preheated air/steam oxidizer location at top of the chamber. This figure shows that by adding more preheated air/steam, the oxygen mass concentration is decreased and, respectively, causes reduction in temperature as it is shown in Figure 7. High reactivity of oxygen with steam due to decrease in coal particle and gas temperature leads to significant reduction for oxygen concentration in reaction volume. Furthermore, concentration of oxygen shows the probability of flame existence in dark blue area, which relates to consumed oxygen during the combustion process.

Figure 9 shows the pollutant NO counters for HiTAC chamber. These contours are prepared for $10 \mathrm{~m} / \mathrm{s}$ coal injection from the $5 \mathrm{~mm}$ diameter nozzle with $1050 \mathrm{~K}$ and $0.02 \mathrm{~kg} / \mathrm{s}$ preheated air injection rate. From this contour, it is observed that NO accumulated in far distance from flame front especially around of it and at the bottom of chamber [25]. The reason for NO contours shape is mainly because of thermal $\mathrm{NO}_{X}$ mechanism which is affected by high temperature in a thin layer around the flame core. In our chamber, it is always reported that some amounts of $\mathrm{NO}$ are trapped at the bottom of chamber as it is visible from numerical results. 


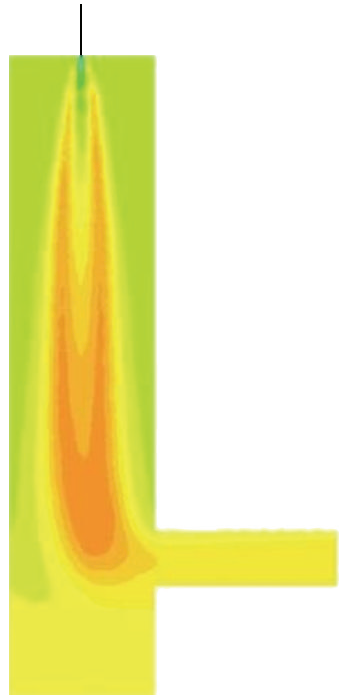

(a) $100 \%$ air

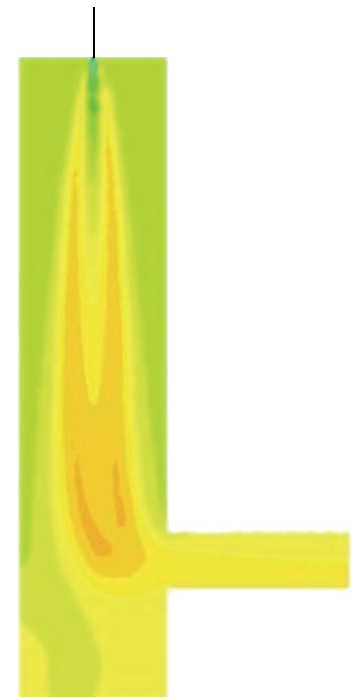

(b) $85 \%$ air $15 \%$ steam

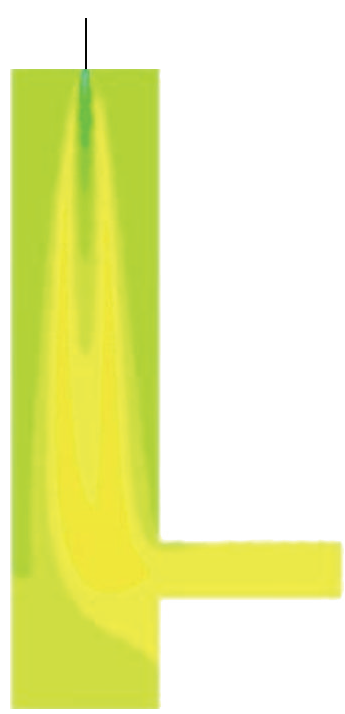

(c) $66 \%$ air $34 \%$ steam

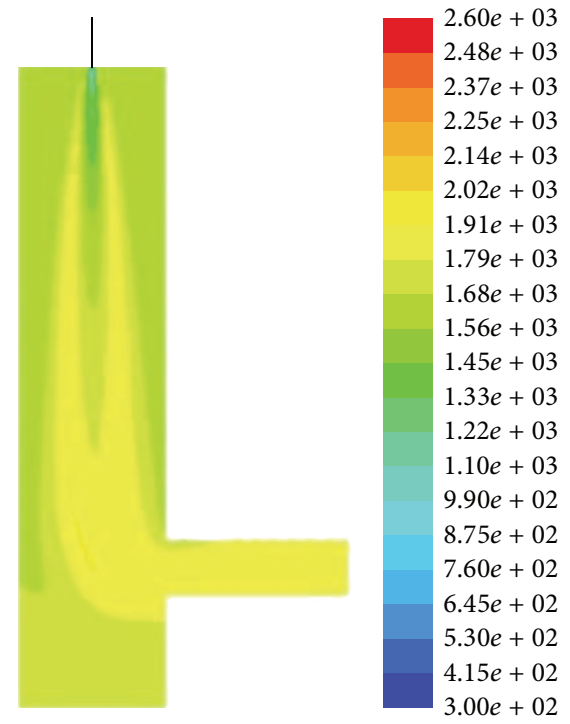

(d) $56 \%$ air $44 \%$ steam

FIGURE 7: Contours of temperature during the combustion chamber (K).

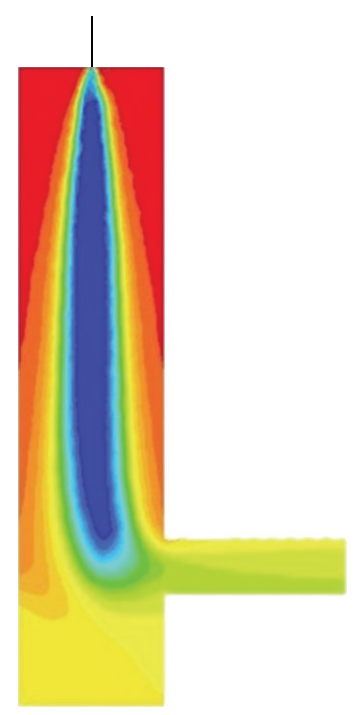

(a) $100 \%$ air

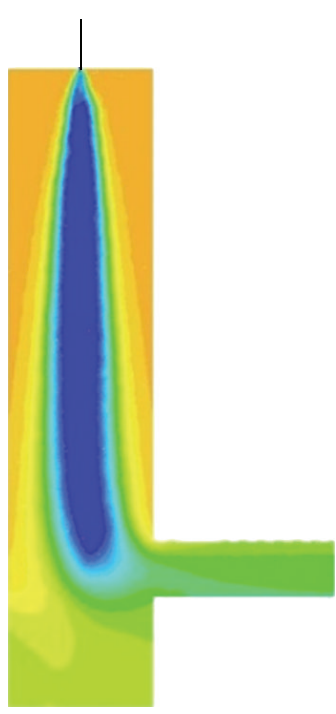

(b) $85 \%$ air $15 \%$ steam

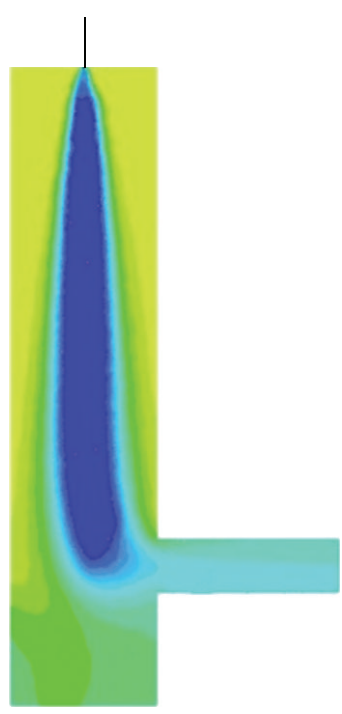

(c) $66 \%$ air $34 \%$ steam

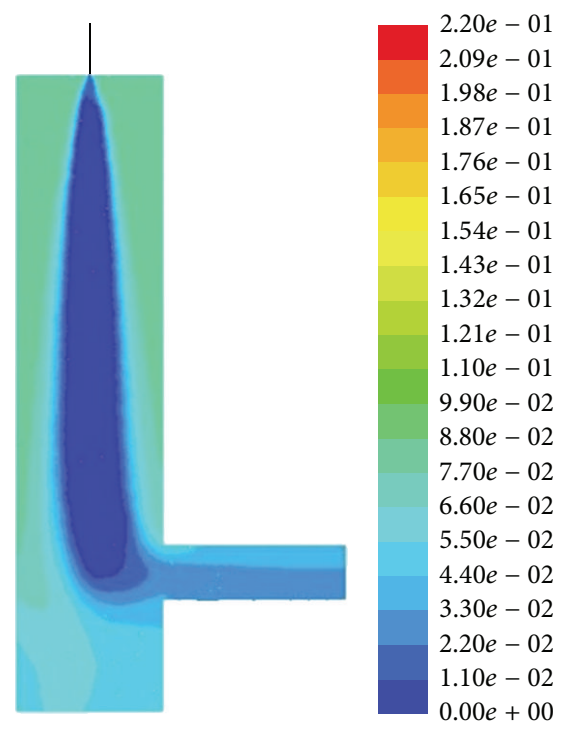

(d) $56 \%$ air $44 \%$ steam

FIGURE 8: Contours of oxygen mass concentration (\%).

4.4. Effect of Oxidizer Injection Rate. Figures 10 and 11 reveal the temperature distribution and NO emission along the combustion chamber center line for different injection rates. In order to evaluate the effects of preheated air injection, coal is injected from the $5 \mathrm{~mm}$ diameter nozzle with $1050 \mathrm{~K}$ and $100 \%$ air composition of oxidizer as the base case.

Figure 10 shows the same trends for all cases in whole chamber. From Figure 10, it is observed that by increasing the amounts of preheated air in oxidizer composition, the temperature will decrease because the huge air concentration in combustion chamber indicates reduction in temperature. On the other hand, by decreasing the preheated air injection rate, the peak temperatures differences are reduced. As it is shown for $0.02 \mathrm{~kg} / \mathrm{s}$ preheated air injection rate due to the enough residence time of particles in volume, the char combustion stage is improved.

Figure 11 illustrates that by increasing the preheated air injection rate, the temperature will decrease due to high concentration of nonreacted air in combustion chamber. Therefore, the direct effect of this reduced temperature leads to less $\mathrm{NO}$ emission. It is also inferred that the peak points of $\mathrm{NO}$ emission will reduce by increasing the rate of injected air. Besides the mentioned effects, the turbulent fluctuations 


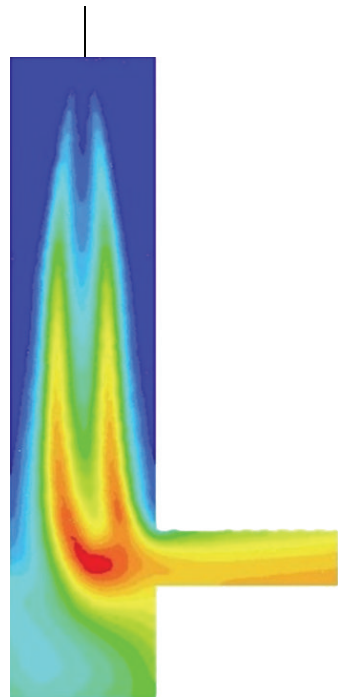

(a) $100 \%$ air

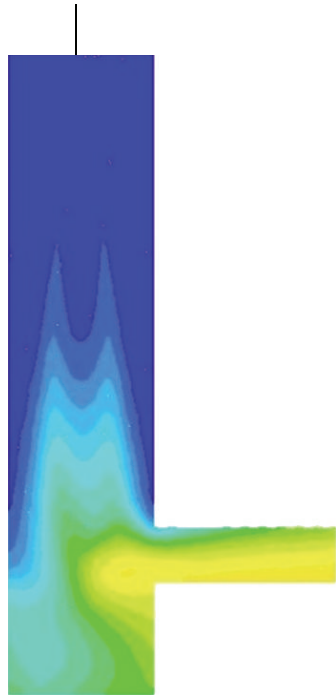

(b) $85 \%$ air $15 \%$ steam

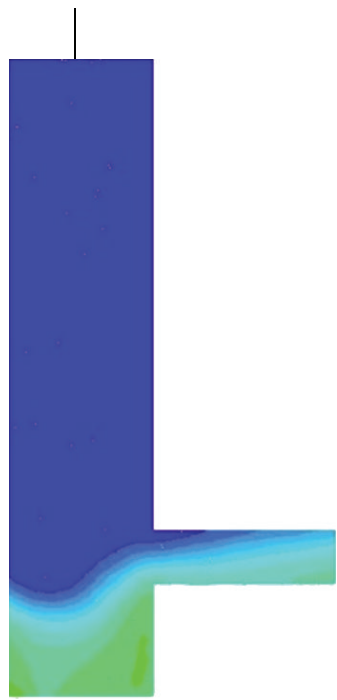

(c) $66 \%$ air $34 \%$ steam

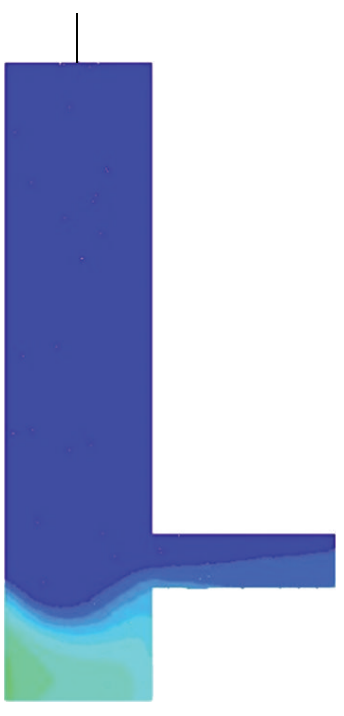

(d) $56 \%$ air $44 \%$ steam
$1.00 e-03$

$9.50 e-04$

$9.00 e-04$

$8.50 e-04$

$8.00 e-04$

$7.50 e-04$

$7.00 e-04$

$6.50 e-04$

$6.00 e-04$

$5.50 e-04$

$5.00 e-04$

$4.50 e-04$

$4.00 e-04$

$3.50 e-04$

$3.00 e-04$

$2.50 e-04$

$2.00 e-05$

$1.50 e-05$

$1.00 e-05$

$5.00 e-06$

$0.00 e+00$

FIGURE 9: Contours of pollutant NO mass concentration (\%).

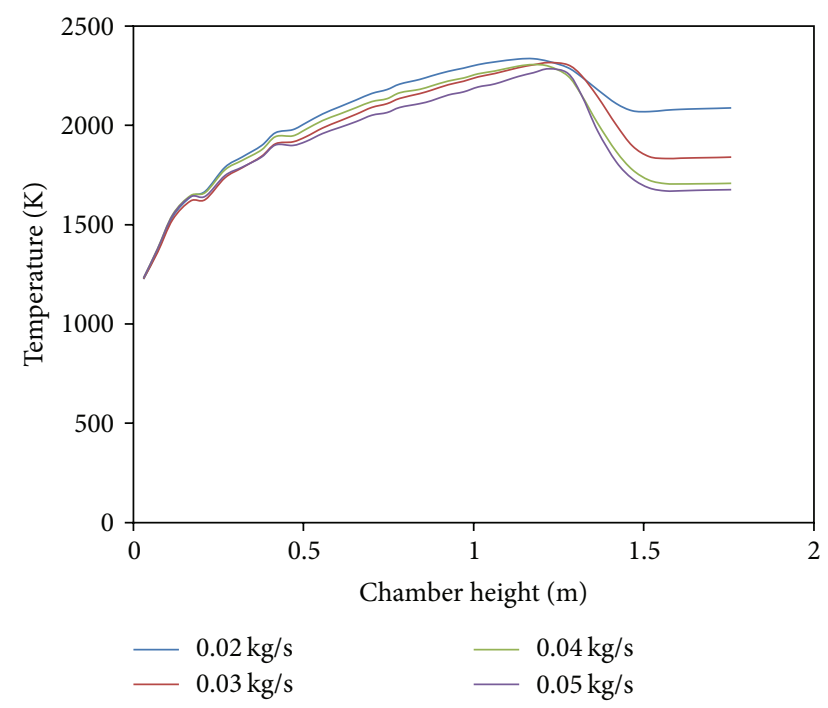

Figure 10: Temperature distribution for different preheated air injection rates.

are also distinguishable near the injection point of nozzle and prolonged to just before major peak points.

4.5. Effect of Fuel Injection Rate. Figure 12 shows that by increasing the amounts of coal injection velocity, the HiTAC chamber reaches to high temperatures because the main fuel is increased. On the other hand, this effect on increasing temperature makes a huge difference at the bottom of chamber and near the exhaust tube. Before the $0.5 \mathrm{~m}$ of full height, the maximum temperature relates to $10 \mathrm{~m} / \mathrm{s}$ fuel injection, because during this region, the low velocity helps to increase the residence time of pulverized particles. Therefore, the

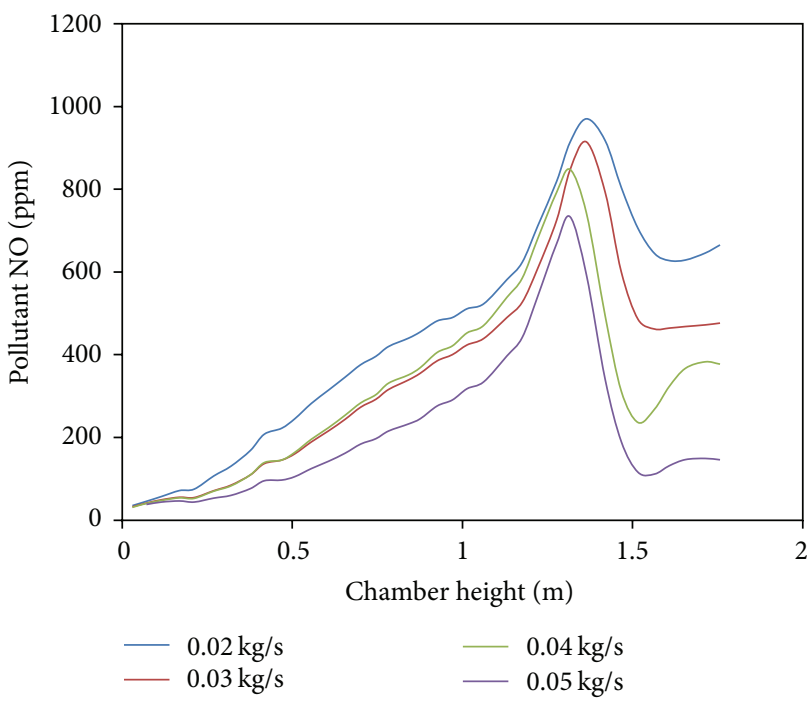

FIGURE 11: Distribution of NO with different preheated air injection rates.

volumetric combustion occurs at high temperature smooth atmosphere. Additionally, based on experience, adding more fuel does not always lead to high temperature, and because of the limitation of fuel air ratio and incomplete combustion, it is important to keep a reasonable balance for them.

Figure 13 presents the NO emission by different fuel injection rates. By increasing the velocity of injected coal, the main fuel increased and $\mathrm{NO}$ emission shows increasing trend. Otherwise, based on coal analysis in Table 1, nitrogen existence in coal composition means that by increasing the fuel rate, the possibility of nitrogen in fuel will increase and lead to high NO emission. The second peak in Figure 13 is 


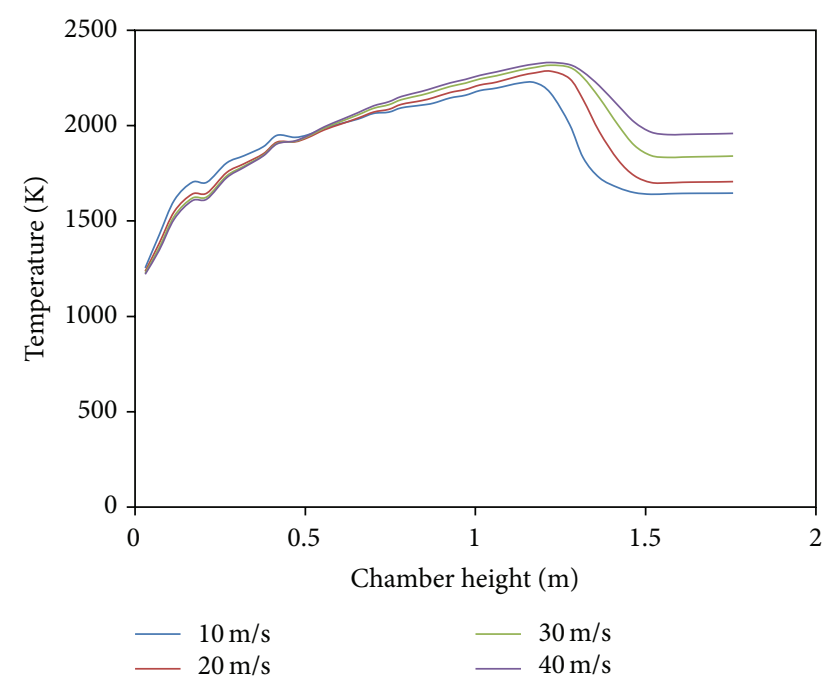

Figure 12: Temperature distribution for different coal velocity injections.

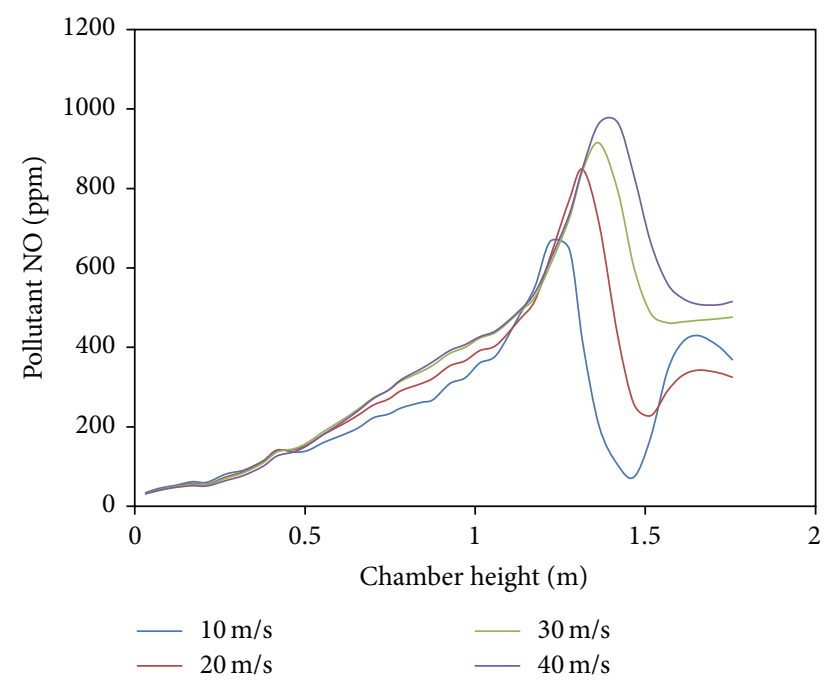

FIGURE 13: Distribution of NO with different coal velocity injections.

related to nonreacted trapped gases that cannot easily pass through the outlet due to their densities.

4.6. Effects of Oxidizer Temperature. In order to investigate the preheated air temperature effects, Figures 14 and 15 are presented. In both figures, coal is injected from the $5 \mathrm{~mm}$ diameter nozzle with $100 \%$ air composition of oxidizer. Figure 14 shows that the temperature distribution in combustion chamber is increased by increasing the preheated air temperature. The main concept of temperature increasing is that by increasing the temperature, the volume and pressure increases. After that, injection of this high pressure preheated air in combustion chamber leads to more volumetric combustion. Otherwise, increasing the temperature of preheated oxidizer helps superior ignition between fuel and oxidizer in higher temperature. The high temperature preheated air

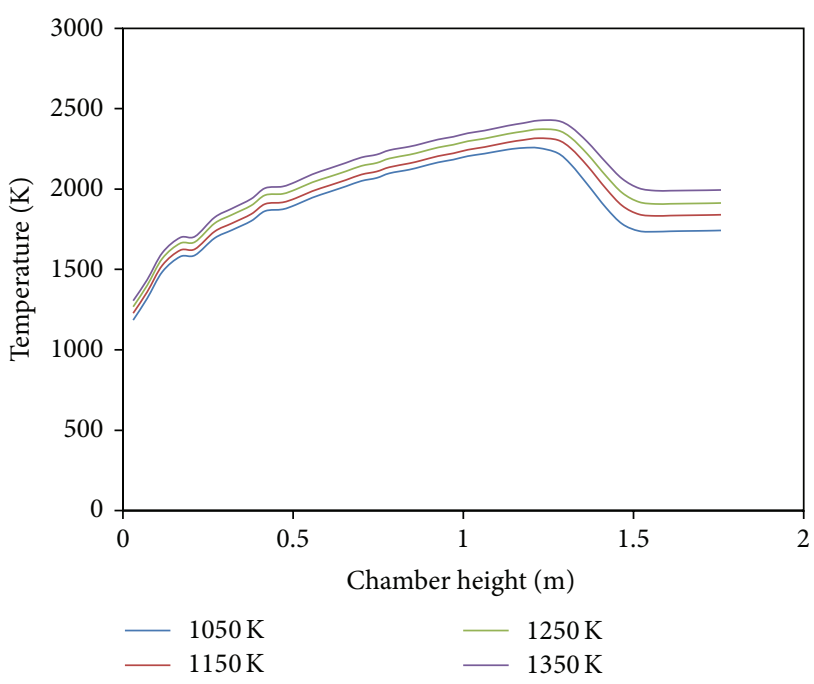

FIGURE 14: Temperature distribution for different preheater's temperatures.

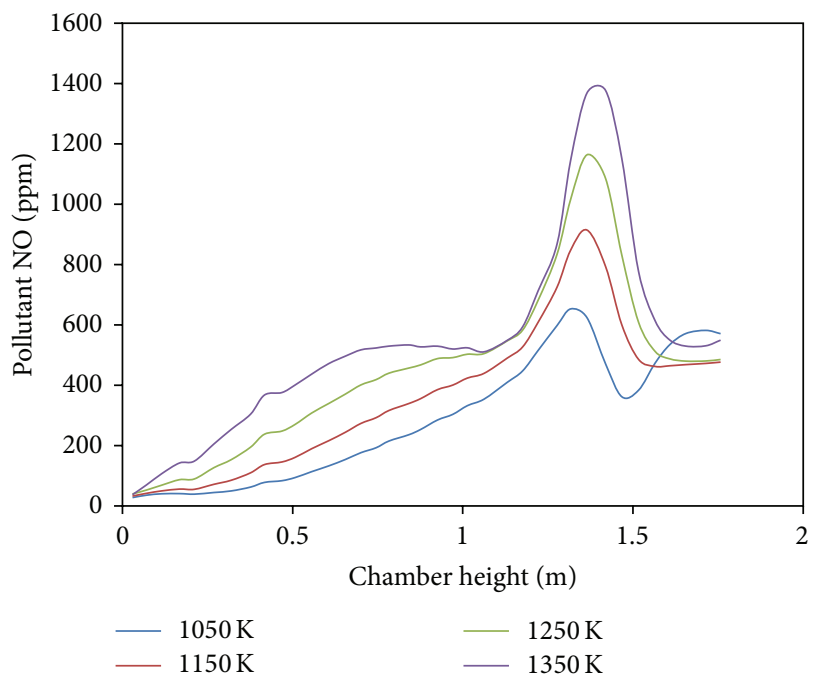

FIGURE 15: Distribution of NO with different preheater's temperatures.

helps to reduce the differences between flame temperatures through entire chamber. Therefore, the whole combustion zones achieve eventual temperature as it is mentioned in Figure 7.

Figure 15 presents NO concentration during the combustion chamber height, which is plotted by different preheated air temperatures. The effect of preheated air on $\mathrm{NO}$ emission is completely the same as what is offered for Figure 14. The same behavior is visible for the whole graphs during the combustion chamber except one more peak in $1050 \mathrm{~K}$ at the end of combustion chamber which illustrates the trapped pollutants at the end of chamber due to low temperature of oxidizer. 


\section{Conclusion}

In this work, both experimental and numerical studies have been performed to study the combustion performance of the pulverized coal in a high preheated air diluted by steam. Validation of numerical results with experimental measurements shows a good consistency in entire regions for both temperature and species. The effects of mixture percentage of air/steam, injection velocity, and preheated temperature have been studied. It is found that

(i) when the steam mixture percentage in preheated air oxidizer compound is increased, the temperature is decreased, the $\mathrm{NO}_{X}$ emission is also decreased, and uniform temperature distribution is achievable;

(ii) when the percentage of steam increased, the visibility of flame due to reduction in temperature decreased, and the flame shape becomes more uniformly with entire chamber;

(iii) when steam percentage increased, the low amounts of soot are achievable which leads to more efficient combustion;

(iv) when the injection rate/speed is increased, two aspects are happening. By increasing the coal injection velocity, the temperature increased and also the $\mathrm{NO}_{X}$ emission increased, but when the preheated air injection rate increased the reverse action was revealed;

(v) when the velocity of preheated air decreased, pulverized injected coal has enough time to react with oxidizer, then the temperature distribution and also volumetric combustion occur more homogeneously;

(vi) when the injected velocity increased, lower equivalence ratio occurred in devolatilization zone; therefore, the $\mathrm{NO}_{X}$ emission is prompted.

\section{Conflict of Interests}

The authors declare that there is no conflict of interests regarding the publication of this paper.

\section{References}

[1] H. Kobayashi, J. B. Howard, and A. F. Sarofim, "Coal devolatilization at high temperatures," Symposium (International) on Combustion, vol. 16, no. 1, pp. 411-425, 1977.

[2] R. Tanaka, "New progress of energy saving technology toward the 21st century, frontier of combustion \& heat transfer technology," in Proceedings of the 11th IFRF, 1995.

[3] T. Hasegawa, R. Tanaka, and T. Niioka, "Combustion with high temperature low oxygen air in regenerative burners," in Proceedings of the 1st Asia-Pacific Conference on Combustion, pp. 290-293, Osaka, Japan, 1997.

[4] T. Yasuda and C. Ueno, "Dissemination project of industrial furnace revamped with HTAC," in Proceedings of the 2nd International Seminar on High Temperature Combustion in Industrial Furnace, Stockholm, Sweden, 2000.
[5] Y. Ito, A. K. Gupta, K. Yoshikawa, and N. Shimo, "Combustion characteristics of low calorific value gas with high temperature and low-oxygen concentration air," in Proceedings of the 5th High Temperature Air Combustion and Gasification Conference, Yokohama, Japan, 2002.

[6] M. Mörtberg, W. Blasiak, and A. K. Gupta, "Experimental investigation of flow phenomena of a single fuel jet in cross-flow during highly preheated air combustion conditions," Journal of Engineering for Gas Turbines and Power, vol. 129, no. 2, pp. 556564, 2007.

[7] H. Tsuji, A. K. Gupta, T. Hasegawa, M. Katsuki, K. Kishimoto, and M. Morita, High Temperature Air Combustion, CRC Press, Boca Raton, Fla, USA, 2003.

[8] D. Szewczyk, M. Mörtberg, N. Rafidi, T. Dobski, and W. Blasiak, "Measurements of temperature and heat flux in HTAC flame for unsteady state condition," in Proceedings of 5th International Symposium on High Temperature Air Combustion and Gasification, pp. 28-30, Yokohama, Japan.

[9] T. Hasegawa, S. Mochida, and A. K. Gupta, "Development of advanced industrial furnace using highly preheated combustion air," Journal of Propulsion and Power, vol. 18, no. 2, pp. 233-239, 2002.

[10] A. K. Gupta, S. Bolz, and T. Hasegawa, "Effect of air preheat temperature and oxygen concentration on flame structure and emission," Journal of Energy Resources Technology, Transactions of the ASME, vol. 121, no. 3, pp. 209-216, 1999.

[11] P. Li, B. B. Dally, J. Mi, and F. Wang, "MILD oxy-combustion of gaseous fuels in a laboratory-scale furnace," Combustion and Flame, vol. 160, no. 5, pp. 933-946, 2013.

[12] J. A. Wünning and J. G. Wünning, "Flameless oxidation to reduce thermal NO-formation," Progress in Energy and Combustion Science, vol. 23, pp. 81-94, 1997.

[13] K. Kökkülünk, G. Gonca, V. Ayhan, I. Cesur, and A. Parlak, "Theoretical and experimental investigation of diesel engine with steam injection system on performance and emission parameters," Applied Thermal Engineering, vol. 54, no. 1, pp. 161170, 2013.

[14] M. S. Ahmed and H. A. Mohamed, "Performance characteristics of modified gas turbine cycles with steam injection after combustion exit," International Journal of Energy Research, vol. 36, no. 15, pp. 1346-1357, 2012.

[15] M. Masi, P. Gobbato, A. Toffolo, A. Lazzaretto, and S. Cocchi, "Numerical and experimental analysis of the temperature distribution in a hydrogen fuelled combustor for a $10 \mathrm{MW}$ gas turbine," Journal of Engineering for Gas Turbines and Power, vol. 133, no. 2, Article ID 021506, 2011.

[16] W. Yang and W. Blasiak, "Mathematical modelling of NO emissions from high-temperature air combustion with nitrous oxide mechanism," Fuel Processing Technology, vol. 86, no. 9, pp. 943-957, 2005.

[17] A. Khoshhal, M. Rahimi, and A. A. Alsairafi, "The CFD modeling of NOx emission, HiTAC and heat transfer in an industrial boiler," Numerical Heat Transfer A: Applications, vol. 58, no. 4, pp. 295-312, 2010.

[18] B. Danon, A. Swiderski, W. De Jong, W. Yang, and D. J. E. M. Roekaerts, "Emission and efficiency comparison of different firing modes in a furnace with four HiTAC burners," Combustion Science and Technology, vol. 183, no. 7, pp. 686-703, 2011.

[19] N. Rafidi and W. Blasiak, "Heat transfer characteristics of HiTAC heating furnace using regenerative burners," Applied Thermal Engineering, vol. 26, no. 16, pp. 2027-2034, 2006. 
[20] A. Khoshhal, M. Rahimi, and A. A. Alsairafi, "Diluted air combustion and NOx emission in a HiTAC furnace," Numerical Heat Transfer A: Applications, vol. 59, no. 8, pp. 633-651, 2011.

[21] ANSYS FLUENT 14.0 Theory guide, 2011.

[22] J. Li, E. Biagini, W. Yang, L. Tognotti, and W. Blasiak, "Flame characteristics of pulverized torrefied-biomass combusted with high-temperature air," Combustion and Flame, vol. 160, no. 11, pp. 2585-2594, 2013.

[23] B. E. Launder and D. B. Spalding, "The numerical computation of turbulent flows," Computer Methods in Applied Mechanics and Engineering, vol. 3, no. 2, pp. 269-289, 1974.

[24] M. F. Modest, Radiative Heat Transfer, Series in Mechanical Engineering, McGraw-Hill, New York, NY, USA, 1993.

[25] S. R. Turns, An Introduction to Combustion Concepts and Applications, McGraw-Hill, New York, NY, USA, 2012.

[26] C. Zou, L. Zhang, S. Cao, and C. Zheng, "A study of combustion characteristics of pulverized coal in $\mathrm{O}_{2} / \mathrm{H}_{2} \mathrm{O}$ Atmosphere," Fuel, vol. 115, pp. 312-320, 2014.

[27] H. Hashemi, S. Hansen, M. B. Toftegaard et al., "A model for nitrogen chemistry in oxy-fuel combustion of pulverized coal," Energy and Fuels, vol. 25, no. 10, pp. 4280-4289, 2011. 

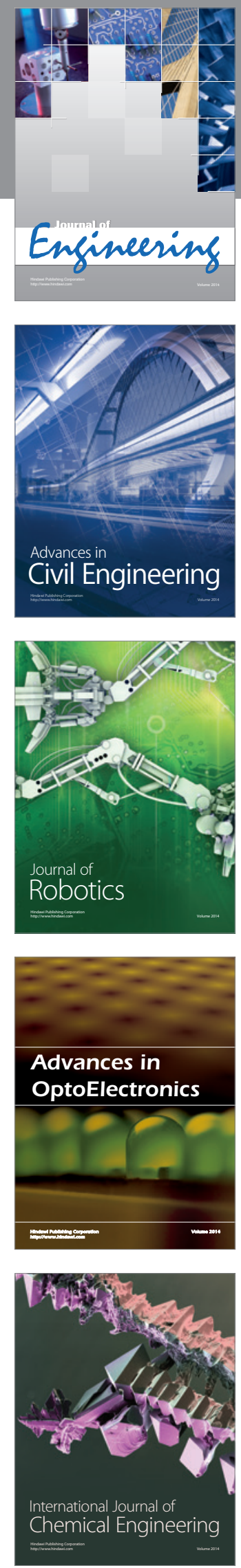

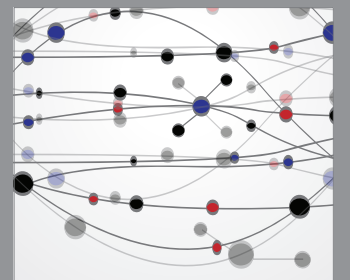

The Scientific World Journal
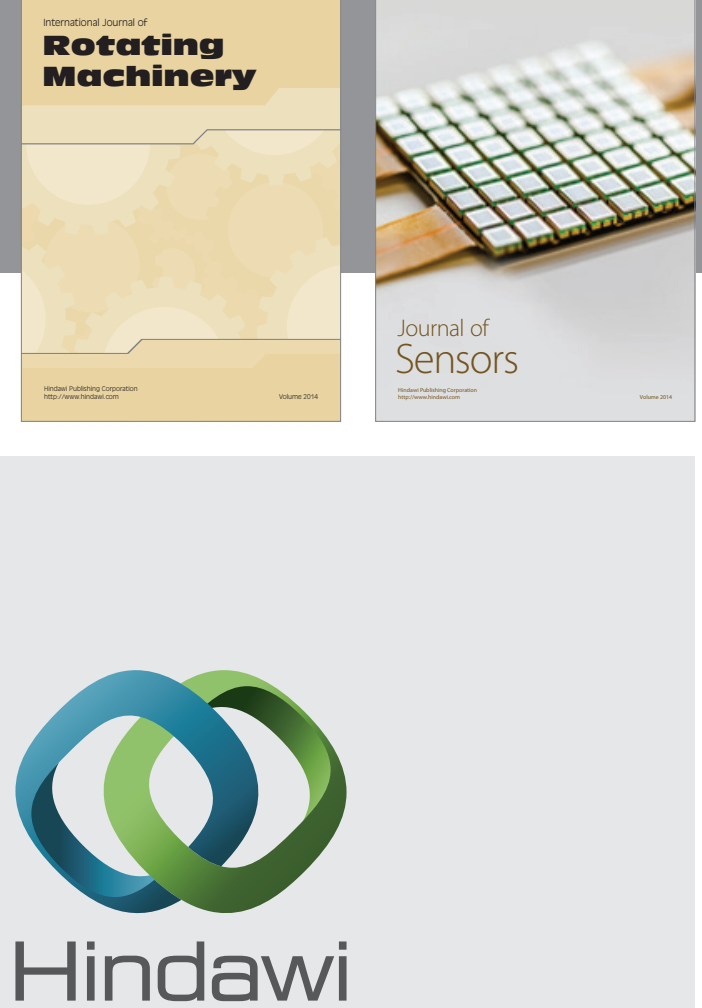

Submit your manuscripts at http://www.hindawi.com
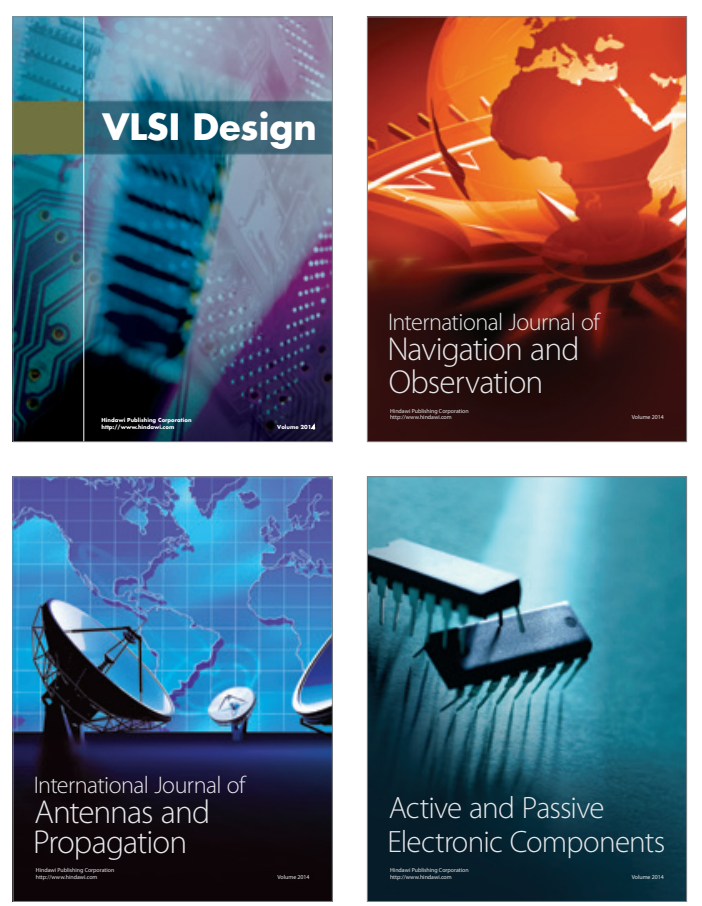
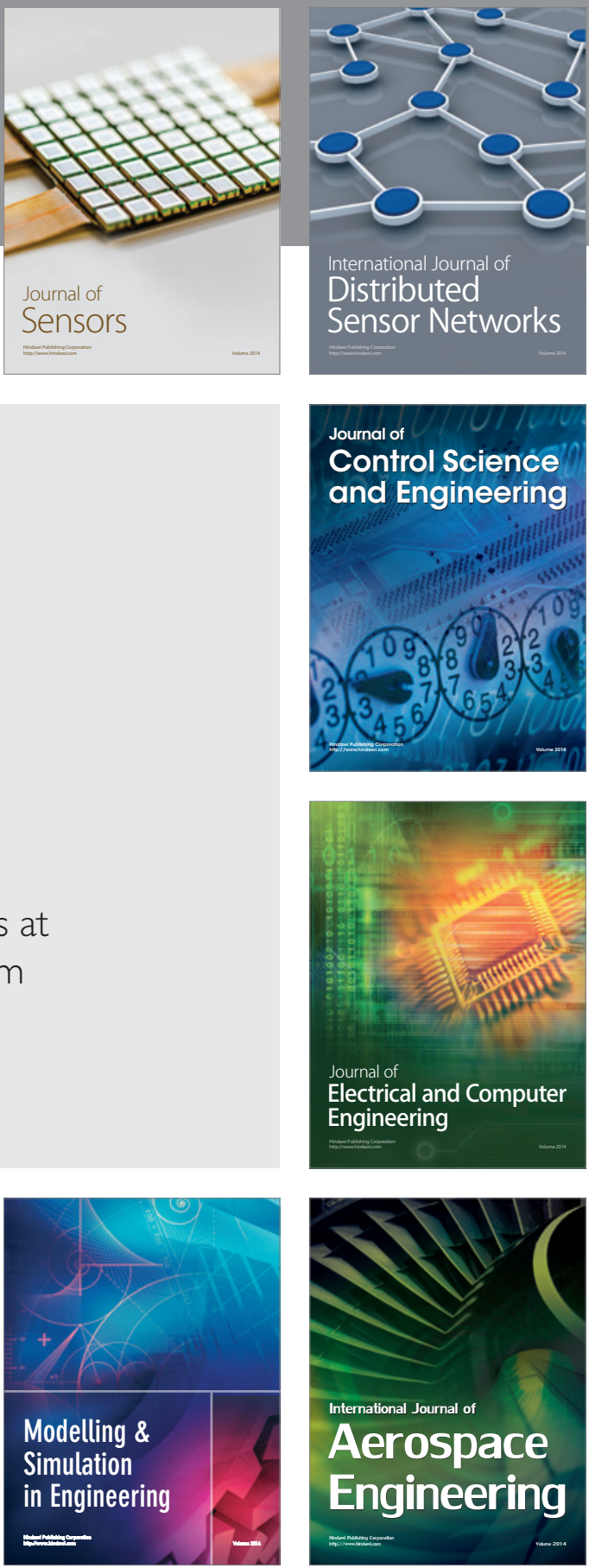

Journal of

Control Science

and Engineering
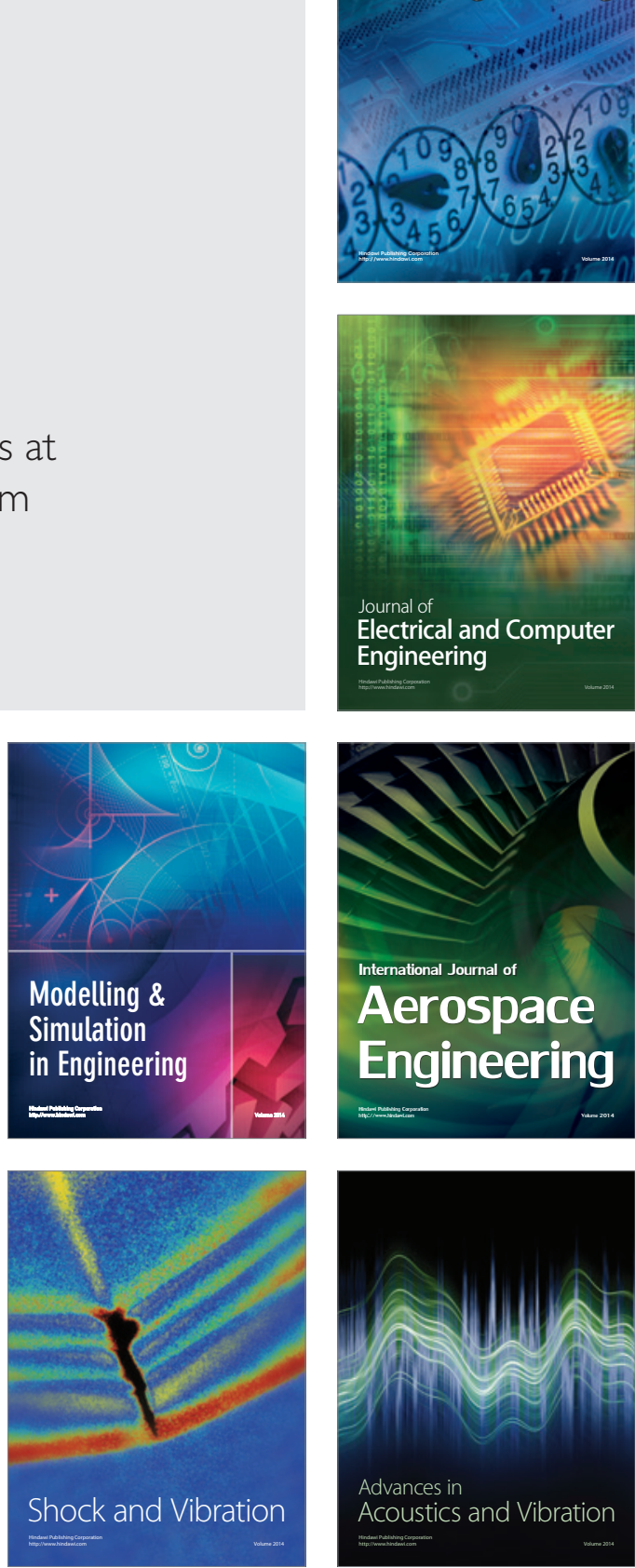